\title{
What's going on in dental education?
}

\author{
Eric S. Solomon, DDS, MA
}

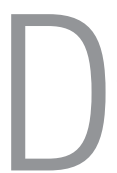

ental education has gone through numerous changes since World War II. These changes have had, and continue to have, a major impact on the practice of dentistry in the United States and Texas.

\section{NATIONAL TRENDS Dental schools}

In 1950, there were 42 dental schools in the US, $60 \%$ of which were affiliated with private universities (Figure 1). With some government assistance and support from a growing applicant pool, the number of dental schools increased to 60 by 1978. Most of this growth was in schools that were affiliated with public universities; they represented $58 \%$ of the schools at that time. However, not all these schools were destined to survive. Beginning in the mid 1970s, the dental school applicant pool began a steep decline. By 1989, the number of applicants to dental school had decreased by two thirds. As a direct or indirect result, six of the dental schools closed-all affiliated with private universities. New dental schools began to open shortly after the turn of the century. By fall 2013, the number of fully operational schools had increased to 64. In addition, several universities around the country are in various stages of planning to open a new dental school, although there is a great deal of uncertainty as to the number of these plans that will come to fruition.

\section{Dental school enrollment}

As might be expected, dental school enrollment follows a pattern similar to the trend in the number of dental schools. Between 1950 and 1971, there was a steady increase in firstyear enrollment in dental schools, totalling $47.1 \%$, or $2.2 \%$ per year (Figure 2). The first-year enrollment growth rate then more than doubled between 1971 and 1978-increasing by $32.8 \%$, or $4.7 \%$ per year. A significant amount of this growth can be attributed to a federal capitation program that began in 1972. Through this program, the federal government gave dental schools approximately $\$ 251.5$ million to build new dental schools, renovate existing schools, and increase enrollment. If this amount were adjusted for inflation, it be would close to a billion dollars today. These funds played a crucial role in updating the dental education infrastructure. As enrollment increased, dental school graduates followed (Figure 2). Between

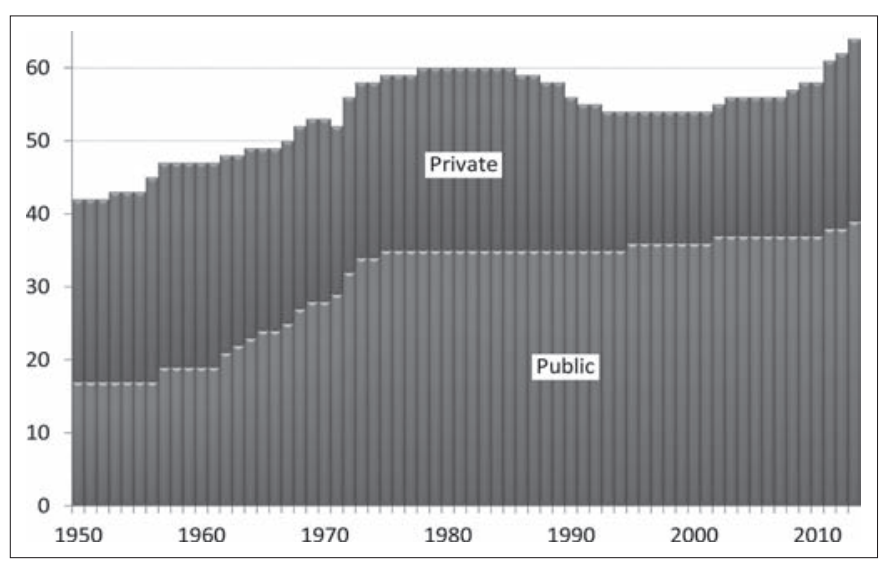

Figure 1. Dental schools by type. Source: American Dental Association, Survey of Dental Education.

1950 and 1975 , the number of dental school graduates increased by $2506(88.6 \%)$.

Enrollment trends generally follow applicant trends; thus, the decline of applicants during the late 1970s and the 1980s had a direct impact on enrollment. First-year enrollment in

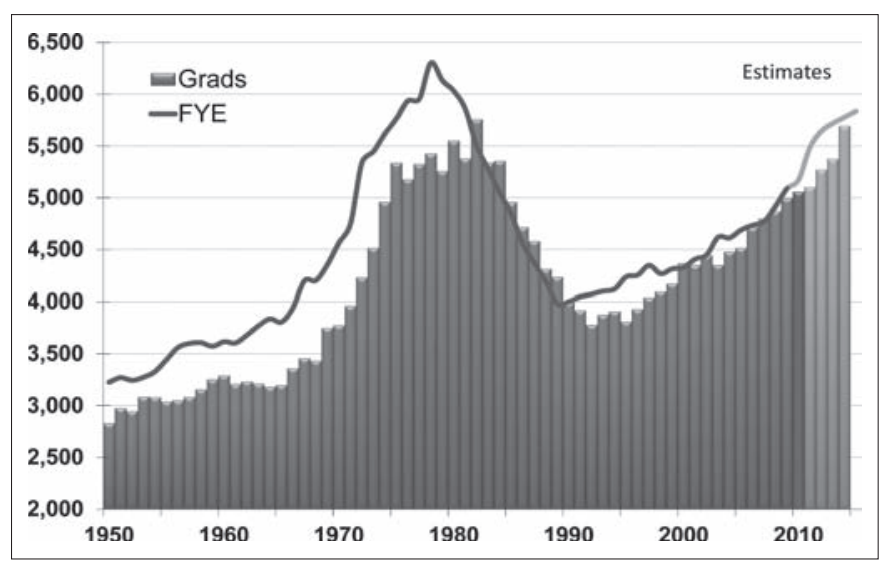

Figure 2. Dental first-year enrollment (FYE) and graduates. Source: American Dental Association, Survey of Dental Education; projection by E. Solomon.

From Texas A\&M Baylor College of Dentistry, Dallas, Texas.

Corresponding author: Eric S. Solomon, DDS, MA, Professor and Executive Director for Institutional Research, Texas A\&M Baylor College of Dentistry, 3302 Gaston Avenue, Dallas, TX 75246 (e-mail: esolomon@bcd.tamhsc.edu). 
dental school peaked in 1978 at 6301 and then dropped to 3979 in 1989 , a decrease of $36.9 \%$. Because of the enrollment buildup, dental school graduates did not begin to fall off until the mid 1980s. Between 1975 and 1984, dental schools graduated more than 5000 dentists a year. By 1990 the number of dental school graduates had dropped to $<4000$ (3995).

The trend in the number of applicants to dental school reversed, and the number of applicants began to increase in 1990. As a result, between 1989 and 2010, first-year enrollment increased from 3979 to 5171 - a 30\% increase. Dental school graduates increased by more than 1000, from 3701 in 1994 to 4496 in 2010 (35\%). With new schools coming on line and some existing schools increasing their class size, it is likely that enrollments and graduates will continue to increase until at least the middle of the decade.

\section{TRENDS IN TEXAS}

In 1970, the University of Texas Health Science Center at San Antonio's dental school accepted its first class. The University of Texas Dental Branch at Houston and the Baylor College of Dentistry had been around since the turn of the past century (1901). Since 1970, these three schools have been the only dental schools in Texas. During the 1970s and 1980s, enrollment trends in Texas schools mirrored the national trends (Figure 3). During the decade of the 1970s, firstyear enrollment in Texas schools almost doubled, increasing from 221 to 417 in 1979. Then, as in the national trend, first-year enrollment fell to 246 in 1993 . First-year enrollment levels were relatively flat for the next 10 years; however, since 2004, enrollment has crept up to almost 300 . Class sizes at

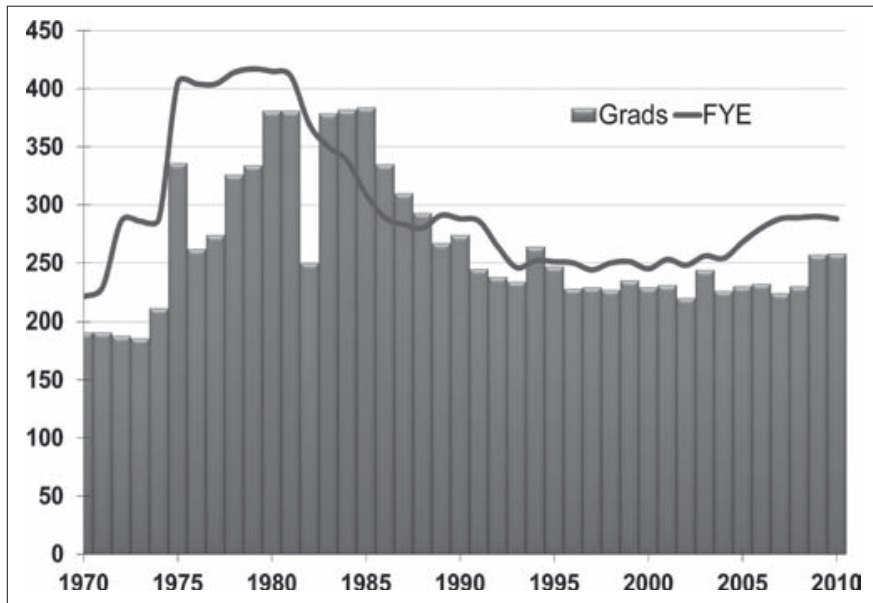

Figure 3. Texas dental first-year enrollment (FYE) and graduates. Source: American Dental Association, Survey of Dental Education.

the three schools are currently fairly similar, with each school having a class size of about 100 students. Naturally, the number of graduates of Texas dental schools follows the first-year enrollment trend. The number of graduates increased from 191 in 1970 to 384 in 1985 and then decreased to 228 in 1996. Since then, the number of graduates has remained fairly consistent, increasing to only 258 in 2010 . Enrollment levels at the Texas dental schools are unlikely to change much over the remainder of the decade. Dental enrollments are limited by the size of facilities. Significant increases in dental school enrollments can only occur if new or expanded clinical facilities are developed. 